(Perbaikan pertemuan ke 8)

\title{
SOSIALISASI BAHAYA SAMPAH PLASTIK BAGI MASYARAKAT \\ DALAM KOMUNIKASI LINGKUNGAN \\ MESSY WINDISARI
}

1910701005

KOMUNIKASI LINGKUNGAN

ILKOM A (2019)

Pencemaran Lingkungan akibat sampah plastik semakin mengkhawatirkan. Masyarakat yang kurang pengetahuan dan berperilaku buruk dalam pengelolaan sampah plastik dapat menimbulkan gangguan kesehatan dan lingkungan karena derajat kesehatan masyarakat ditentukan oleh kondisi pejamu, agent (penyebab penyakit), dan lingkungan .

Sampah plastik yang berbahaya dan sulit dikelola memerlukan waktu yang cukup lama untuk membuat sampah plastik benar-benar terurai. Sampah plastik yang tidak bisa terurai oleh bakteri merupakan masalah yang serius bagi pencemaran lingkungan. Dalam Undang Undang Nomor 18 Tahun 2008 Tentang Pengelolaan Sampah, bahwa pertambahan penduduk dan perubahan pola konsumsi masyarakat menimbulkan bertambahnya volume, jenis, dan karakteristik sampah yang semakin beragam kini perlu perubahan cara pandang masyarakat mengenai sampah dan cara memperlakukan atau mengelola sampah. Pada konsep Hendrik Blum, faktor lingkungan merupakan unsur penentu kesehatan

Dalam studi yang dilakukan oleh UN Environment Programme (UNEP) berjudul "Single-Use Plastics: A Roadmap for Sustainabil-ity” pada tahun 2018 mengungkapkan, bahwa sampah plastik berupa kantong dan styrofoam memerlukan ribuan tahun untuk bisa terurai. Menurut Asosiasi Industri Olefin Aromatik dan Plastik Indonesia (INAPLAS), 65 persen konsumsi plastik nasional masih didominasi oleh plastik kemasan. Dari total permintaan plastik kemasan, sekitar 60 persen diserap oleh industri makanan dan minuman.

Plastik adalah istilah umum bagi polimer, yaitu material yang terdiri dari rantai panjang karbon dan elemen-elemen lain (oksigen, nitrogen, klorin atau belerang) yang mudah dibuat menjadi berbagai bentuk dan ukuran. Plastik dibuat dengan cara 
polimerisasi yaitu menyusun dan membentuk bahan-bahan dasar plastik (monomer) secara sambung-menyambung (Setyablogku, 2012)

\section{A.Penggunaan Plastik Dalam Kehidupan Sehari-hari}

Pada kehidupan sehari-hari, kita pasti sudah tidak jarang lagi melihat hal-hal yang terbuat dari plastik, baik itu sebagai kemasan makan sampai sebagai pembawa barang belajaan. Penggunaan kemasan plastik sebagai pembungkus makanan saat ini bisa dikatakan terus meningkat setiap harinya. Hal ini dapat disebabkan karena kebutuhan manusia yang tidak pernah berhenti untuk terus menggunakan kemasan plastik. Padahal kita semua tahu bahwa sampah plastik merupakan bahan yang sulit terurai di tanah dan memerlukan waktu kurang lebih 1000 tahun untuk dapat menguraikannya. Akan tetapi karena plastik dianggap sebagai kemasan yang sangat praktis untuk digunakan terutama dalam membungkus makanan maka penggunaannya pun terus meningkat dari hari ke hari. Meningkatnya penggunaan kemasan plastik ini ternyata menyebabkan berbagai macam permasalahan lingkungan seperti semakin bertambahnya volume sampah plastik di TPS maupun di TPA, tersumbatnya saluran drainase oleh sampah plastik sehingga dapat menyebabkan banjir, menyebabkan perubahan iklim akibat pembakaran sampah yang dilakukan, dan mencemari tanah dan air tanah.

Hampir setiap hari kita pasti membutuhkan plastik tanpa sadar akan sampahnya. Bisa kita perhitungkan berapa besar penggunaan plastik setiap harinya. Banyak masyarakat yang menggunakan plastik sebagai pembungkus makanan. Misalnya saja saat membeli gorengan, pasti dibungkus menggunakan plastik atau saat kita berbelanja di minimarket pasti alat yang digunakan untuk membawa barang belanjaan kita adalah plastik. Kesadaran masyarakat untuk meminimalkan penggunaan plastik pun masih sangat kurang, padahal bahaya yang akan dihadapi dari sampah plastik pun sebagian dari mereka telah mengetahui.

\section{B. Cara Penanggulangan Penggunaan Plastik.}

Dibalik segala dampak buruk yang dibawa oleh penggunaan plastik, ternyata terdapat beberapa cara yang dapat kita lakukan untuk mengurangi penggunaan plastik sehingga dampaknya pun terkurang. Berikut merupakan beberapa cara penanggulangan plastik yang bisa kita lakukan: 
1. Bawa Reusable Bag ( tas ramah lingkungan) saat bepergian selain ramah lingkungan juga cocok dibawa kemana saja.

2. Bawa Tumbler atau Lunch Box sendiri saat ke sekolah atau ke kantor selain hemat, juga meminimalisir sampah plastik berbahaya, dan berpartisipasi dalam diet kantong plastik.(Wahyudin, 2017)

Mungkin cara-cara ini belum dilakukan oleh banyak orang, namun kita bisa mulai melakukan hal ini dari diri kita sendiri dahulu, sehingga bisa menjadi contoh dan bisa dilakukan oleh orang lain. Agar semakin banyak orang yang melakukan hal ini untuk lingkungan yang tetap terjaga pada masa depan. Karena, walaupun tindakan tersebut hanya tindakan kecil tapi bisa berpengaruh besar terhadap lingkungan.

Seperti pendapat dari (Yenrizal, 2016) "ketika masyarakat bisa menjaga lingkungan dan merawat lingkungan dan saling bergantung satu sama lain disitu lah makna dari komunikasi lingkungan yang mana manusia bisa beinteraksi langsung kepada lingkungan".Proses komunikasilingkungan terjadi karena adanya kesadaran dari diri manusia.

Harus mempunyai kesadaran terhadap lingkungan dan membatasi penggunaan sampah plastik karena sangat susah diurai sebagai generasi muda kita harus bisa mengelola sampai plastik dengan cara menggunakan bekas plastic itu membuat tas plastik dan lainnya.(Yenrizal \& dan Johan Iskandar, 2016)

Dalam artikel yang dibuat oleh Yenrizal(2015) mengungkapakan bahwa proses komunikasi lingkungan masyarakat dalam memandang sawah sebagai pertanian utama. Melalui pendekatan etnoekologi komunikasi, penelitian ini menunjukkan bahwa masyarakat melakukan proses konstruksi simbol tersendiri terhadap sawah, yang kemudian dianggap punya makna tersendiri, yaitu makna kesejahteraan, makna kekuasaan, dan makna identitas. Semua makna-makna tersebut tidaklah terjadi dengan sendirinya, namun sebuah proses komunikasi masyarakat dalam memaknai lingkungan alamnya, khususnya eksistensi sawah

\section{Kesimpulan}

Permasalahan sampah di Indonesia ini sampai sekarang masih sulit di pecahkan karena penggunaan sampah plastik sampai saat sekarang sangat lah meningkatkan bahkan pemerintah sudah pada pada masyarakat setempat mereka mempunyai upaya untuk memperkuat kelembagaan lokal karena itu sangat mempengaruhi terhadap tatanan sosial 
budaya dan ekosistem di sebuah komunitas kelembagaan lokal yang pertama adalah bagan ada tunggu tubang yang ada di setiap keluarga besar upaya memperkuat kan dapat mendorong kan dari dalam masyarakat internal ataupun eksternal secara internal mereka harus melakukan harus melakukan kalangan manajer dan tunggu tubang dengan senantiasa Mengingatkan untuk memberi arahan kepada seluruh dihilangkan.

Mata Pencaharian masyarakat setempat adalah petani jadi masyarakat sangat memperhatikan Komunikasi Lingkungan supaya mereka bisa mengatasi kemiskinan di daerah mereka.

menyiapkan beberapa bak sampah dan cara menanggulanggikan namun sampai saat ini masih belum bisa dipecahkan .Sebagai generasi muda kita harus bisa melakukan hal hal kecil dimulai dari diri kita sendiri biasakan mengurangin sampah plastik jika kita gunakan kita bisa mendaur ulangnya .Kita peran penting didalam komunikasi lingkungan merupakan interaksi kepada lingkungan yang mana kita dengan lingkungan sangat bergantung . 


\section{DAFTAR PUSTAKA}

Yenrizal, Agus Rahmat, Atwar Bajari, and Johan Iskandar. "MAKNA SIMBOLIK SAWAH DI MASYARAKAT PEDESAAN TINJAUAN KOMUNIKASI LINGKUNGAN PADA MASYARAKAT SEMENDE DARAT TENGAH KABUPATEN MUARA ENIMSUMATERA SELATAN." Jurnal Kawistara 5.3 (2015). https://doi.org/10.22146/kawistara.10057

Asteria, Donna, and Heru Heruman. "Bank sampah sebagai alternatif strategi pengelolaan sampah berbasis masyarakat di Tasikmalaya (Bank Sampah (Waste Banks) as an alternative of community-based waste management strategy in Tasikmalaya)." Jurnal manusia dan lingkungan 23.1 (2016): 136-141. https://doi.org/10.22146/jml.18783

Adiwijaya, Michael. Peran pemerintah, industri ritel, dan masyarakat dalam membatasi penggunaan kantong plastik sebagai salah satu upaya pelestarian lingkungan. Diss. Petra Christian University, 2011. https://doi.org/10.18196/bdr.6244

dan Johan Iskandar, Y. A. R. A. B. (2015). Makna Simbolik Sawah Di Masyarakat Pedesaan Tinjauan Komunikasi Lingkungan Pada Masyarakat Semende Darat Tengah Kabupaten Muara Enim-Sumatera Selatan. Jurnal Kawistara, 5(3), 120-129. https://doi.org/10.22146/kawistara.10057 Yenrizal, Y. (2016). SUNGAI DALAM PEMAKNAAN MASYARAKAT PEDESAAN STUDI ETNOEKOLOGI KOMUNIKASI PADA MASYARAKATDESA KARANG ANYAR, BANYUASIN .... Jurnal Nizham. http://repository.radenfatah.ac.id/6905/ 
